\title{
Analysis of caesarean rate, indications and complications: review from medical college Ambala, Haryana, India
}

\author{
Shweta $\operatorname{Yadav}^{1}$, Simmanjit Kaur ${ }^{3}$, Sachin Singh $\operatorname{Yadav}^{2}$, Bhumika Thakur $^{3}$
}

\author{
${ }^{1}$ Department of Obstetrics and Gynaecology, ${ }^{2}$ Department of Community Medicine, Teerthankar Mahaveer Medical \\ College, Moradabad, Uttar Pradesh, India \\ ${ }^{3}$ Department of Obstetrics and Gynaecology, MMIMSR, Mullana, Ambala, Haryana, India
}

Received: 10 September 2016

Accepted: 16 September 2016

\section{*Correspondence:}

Dr. Shweta Yadav,

E-mail: shweta_6279@rediffmail.com

Copyright: () the author(s), publisher and licensee Medip Academy. This is an open-access article distributed under the terms of the Creative Commons Attribution Non-Commercial License, which permits unrestricted non-commercial use, distribution, and reproduction in any medium, provided the original work is properly cited.

\begin{abstract}
Background: Cesarean section remains the most commonly performed obstetric surgery but indications of it have been changed. Earlier it used to be done for health of the mother but now fetal interest has played a major role. The aim of the study was to find out incidence, indication of LSCS, maternofetal outcome in our rural medical college.

Methods: This retrospective study was conducted at MMIMSR Mullana, Ambala, Haryana, India between $1^{\text {st }}$ April $2015-30^{\text {th }}$ March 2016. All women admitted for delivery in OBG department via OPD or emergency were taken in the study.

Results: The total no of deliveries was 2196. There were 474 (21.6\%) case of caesarean sections (LSCS). Among them $156(32.9 \%)$ patients had elective LSCS, and $318(67.1 \%)$ had emergency LSCS. Mean age of the study was 27.2 years. Fetal distress was the commonest indication of LSCS $(25.1 \%)$ followed by pregnancy with previous LSCS. Post-partum hemorrhage (PPH) and adhesion were commonly encountered complications.

Conclusions: LSCS due to maternal fetal indication is inevitable. Timely performed LSCS decrease the morbidity and mortality. Government also has taken initiative in making cesarean deliveries more acceptable and affordable to patients belonging to the rural areas.
\end{abstract}

Keywords: LSCS, Elective LSCS, Emergency LSCS, Fetal distress, PPH

\section{INTRODUCTION}

Caesarean delivery is defined as the birth of a live or dead fetus through incisions in the abdominal wall (laparotomy) and the uterine wall (hysterotomy) cesarean delivery is one of the most commonly performed operations today. ${ }^{1}$ The indications for cesarean sections have been undergoing a gradual change over the last few decades. Besides the obstetric causes, several other medical, social, ethical, economic and medico legal factors play a role in this rising trend of caesarean section. Initially it was performed mainly for maternal interest but recently the health of the fetus has played a significant role in making the decision for a caesarean birth. $^{2}$
CS may be associated with short term and long term risks. Short-term maternal risks associated with CS include bleeding, injury of urogenital or gastrointestinal organs, postoperative infection and an increased risk for deep venous thrombosis. In long term there are increased risks of severe bleeding following uteroplacental complications such as placenta previa and placenta accreta in subsequent pregnancies. ${ }^{1,3}$ While newborn may face problems like neonatal respiratory distress including transient tachypnea and persistent pulmonary hypertension. ${ }^{4}$

Elective caesarean is a term used when the procedure is done at a pre-arranged time during pregnancy to ensure the best quality of obstetrics, anesthesia, neonatal 
resuscitation and nursing services. The procedure is termed as emergency caesarean section when it is performed due to unforeseen or acute obstetric emergencies. ${ }^{5}$ It is seen that morbidity and mortality are associated more with emergency procedures than with elective procedures. ${ }^{6}$

Proportion of CS to the total births is considered as one of the important indicators of emergency obstetric care (World Health Organization, 2009). ${ }^{7}$ A figure below 5\% implies that a substantial proportion of women do not have access to surgical obstetric care; on the other hand a rate higher than $15 \%$ indicates over utilization of the procedure for other than life saving reasons (WHO, 1985; WHO, 1993). ${ }^{8}$ Based on the WHO systematic review, increases in caesarean section rates up to $10-15 \%$ at the population level are associated with decrease in maternal, neonatal and infant mortality. ${ }^{9}$

In India the rate of caesarean section delivery has increased from 3 per cent to 10 per cent between 1992-93 and 2005-06 (IIPS, 2007) which are lower compared to some developing nations like Brazil and China. ${ }^{10}$ But as India is the second most populous country in the world, a small percentage increase affects a huge number of people. Based on DLHS-3 data, the caesarean section delivery rate in India is 9.2 per cent. ${ }^{11}$

This study was done to done to find out incidence of caesarean section, clinical profile of women undergoing $\mathrm{CS}$, indication of CS, maternal and fetal outcome in our rural medical college.

\section{METHODS}

This retrospective study was conducted at MMIMSR Mullana, Ambala, Haryana, India from $1^{\text {st }}$ April 2015 to $30^{\text {th }}$ March 2016. All women admitted for delivery in the Obst and Gynae department via OPD or emergency were taken in the study. These cases were traced through the registers kept in labour room, postnatal wards, and OT. The labour register was used to determine the number of deliveries during the study period.

All caesarean sections performed at the hospital during the one year period were included in the study. There was no exclusion criterion.

Each patient's data was obtained from their case records kept in medical records department. Data were collected in a preconceived format with special emphasis on demographic details like age, parity, booking status; antenatal high risk factors; indication of the caesarean section; timing of caesarean section; intra-operative and postpartum complications; apgar score of the baby; neonatal intensive care unit (NICU) admission; birth weight and neonatal morbidity/mortality.

The data obtained was entered in MS excel sheet and tabulated.

\section{RESULTS}

Total number of deliveries in our MMIMSR during study period was 2196; there were $474(21.6 \%)$ cases of caesarean section. Among them 156 (32.9\%) patients had elective LSCS while rest $318(67.1 \%)$ needed surgery in emergency.

Mean age of our study participants was 27.2 year. As depicted in Table 1 maximum $(36.5 \%)$ patient were between 26- 30 year age group, while 61 (12.9\%) women were young parturient ( $<20$ year ) and only $8(1.7 \%)$ women were elderly (>36 years). Our most $(69.8 \%)$ patients were from rural background.

Table 1: Socio demographic profile.

\begin{tabular}{|lll|}
\hline Age & Number & Percentage \\
\hline$<20$ & 61 & 12.9 \\
\hline $20-25$ & 159 & 33.5 \\
\hline $26-30$ & 173 & 36.5 \\
\hline $31-35$ & 73 & 15.4 \\
\hline$>36$ & 8 & 1.7 \\
\hline Residence & & \\
\hline Rural & 331 & 69.8 \\
\hline urban & 143 & 30.2 \\
\hline
\end{tabular}

Figure 1 shows distribution of patients according to their previous delivery status, $183(39 \%)$ patients were nulliparaous, 43(9\%) were grand multiparaous $(>4)$.

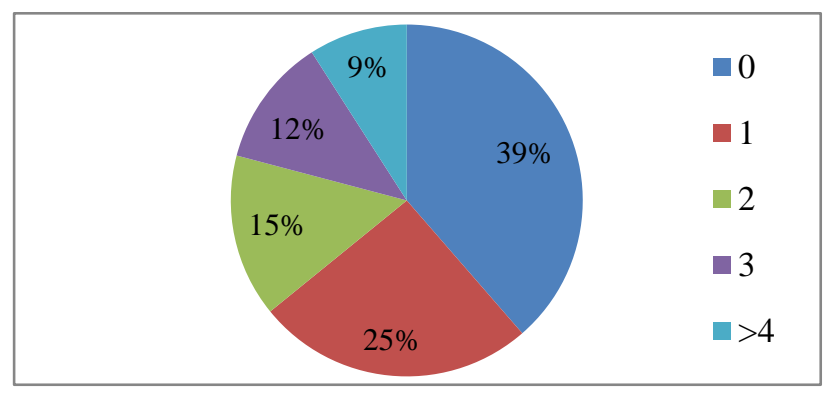

Figure 1: Distribution cases as per parity.

Table 2 depicts details of indication for LSCS. Fetal distress was the commonest indication as 119 (25.1\%) women had LSCS for the same. 105 (22.2\%) patients had history of cesarean section in last pregnancies out of which 79 had 1 LSCS, 17 had 2 and 9 women had 3 LSCS. Among preexisting obstetric indications hypertensive disorders of pregnancy contributed to LSCS in $87(18.3 \%)$ patients, $39(8.2 \%)$ had ante partum eclampsia. Antepartum hemorrhage (APH) was the indication of surgery in $46(9.7 \%)$ among them placenta previa was found in $31(6.5 \%)$ cases. Malpresetation was the sole indication in $26(5.4 \%)$.

Details of intra operative or post-operative complication encountered by patients is revealed in Table 3, adhesion 
was the commonest complication which was present in 69 repeat LSCS, while atonic post-partum hemorrhage was most commonly met complication contributing in $41(8.6 \%)$ patients irrespective of previous surgical history.

Table 2: Indication of LSCS.

\begin{tabular}{|lll|}
\hline Indication & Number & Percentage \\
\hline Fetal distress & 119 & 25.1 \\
\hline Prev lscs & 79 & 16.6 \\
\hline Prev 2 lscs & 17 & 3.6 \\
\hline Prev 3 lscs & 9 & 1.9 \\
\hline Malpresenttion & & \\
\hline Transverce lie & 7 & 1.5 \\
\hline Breech & 18 & 3.8 \\
\hline Oblique lie & 1 & 0.2 \\
\hline PIH & 48 & 10.1 \\
\hline Eclampsia & 39 & 8.2 \\
\hline BOH & 16 & 3.4 \\
\hline Twin & 5 & 1.1 \\
\hline IUGR & 23 & 4.9 \\
\hline Failed induction & 9 & 1.9 \\
\hline $\begin{array}{l}\text { Oligoamnios with fertal } \\
\text { distress }\end{array}$ & 7 & 1.5 \\
\hline Non progress of labour & 29 & 6.1 \\
\hline Cord prolapse & 2 & 0.4 \\
\hline Placenta previa & 31 & 6.5 \\
\hline Abruptio placentae & 15 & 3.2 \\
\hline
\end{tabular}

Table 3: Maternal complications.

\begin{tabular}{|lll|}
\hline Complication & Number & Percentage \\
\hline Intraoperative & & \\
\hline Atonic PPH & 41 & 8,6 \\
\hline Extension of uterine incision & 15 & 3.2 \\
\hline Injury to baldder & 1 & 0.02 \\
\hline Adhesion & 69 & 14.6 \\
\hline Hematuria & 73 & 15.4 \\
\hline Postoperative & & \\
\hline Abdominal distension & 57 & 12 \\
\hline Fever & 126 & 26.6 \\
\hline Prolonged cathaterisation & 91 & 19.2 \\
\hline UTI & 76 & 16 \\
\hline Wound discharge & 65 & 13.7 \\
\hline Resuturing of wound & 12 & 2.5 \\
\hline
\end{tabular}

Extension of uterine incision occurred in 15 (3.2\%) cases and 1 case had urinary bladder injury for which immediate bladder repair was done. Although transient hematuria was present in $73(15.4 \%)$ cases which resolved spontaneously in immediate post-operative period. Post operatively fever was the most common complication, prolonged catheterization due to either adhesion, prolonged labour or hematuria was needed in $91(19.2 \%)$ patients. $65(13.7 \%)$ patients had wound discharge post operatively most of them responded to antibiotic change and only $12(2.5 \%)$ cases required resuturing of gapped wound.

In present study $22(4.6 \%)$ babies of these cases were lost among them 7 were IUD, 1 was still born and 14 had early neonatal death. Neonatal jaundice was the most common (215 babies) complication followed by sepsis then birth asphyxia (Figure 2).

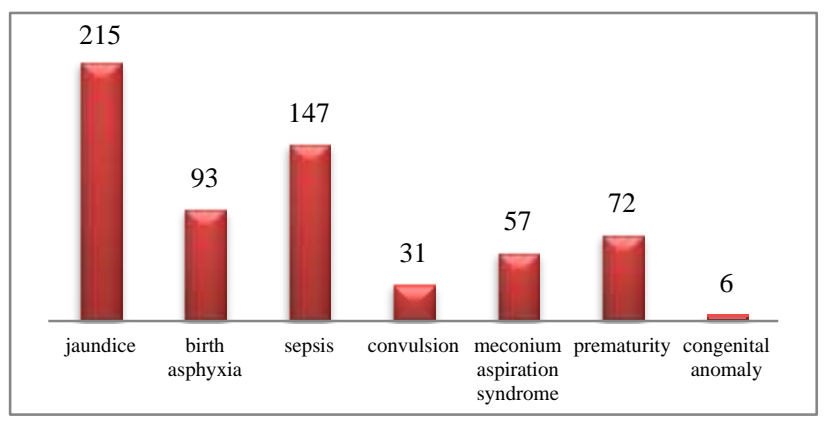

Figure 2: Neonatal complications.

\section{DISCUSSION}

The incidence of cesarean section during one year study is $21.6 \%$ out of them $156(32.9 \%)$ patients had elective LSCS while rest $318(67.1 \%)$ needed surgery in emergency. Our results are similar to earlier reports from other medical colleges of India on the contrary Daniel S et al reported higher incidence (total 28.7\%) elective $46.06 \%$ and $53.9 \%$ ) although the observed incidence in our study is far lower than reported from sub-Saharan countries. ${ }^{2,11,13,14}$ In Asia survey the overall cesarean rate was $27.3 \%$. China had the highest overall cesarean rates (46.2\%) followed by Vietnam, Thailand and Sri Lanka; Cambodia had the lower $(14.7 \%){ }^{15}$

Mean age of our study participants was 12.16 years with maximum (36.5\%) patient between 26-30 year age group, which was comparable with other studies, in our study $183(39 \%)$ patients were nulliparous, primary cesarean rate was quite high $(88.8 \%)$ in our study then earlier studies. ${ }^{2,13}$ Fetal distress was the commonest indication $(25.1 \%)$ of LSCS in our study, followed by previous cesarean section (22.2\%). Among preexisting obstetric indications hypertensive disorders of pregnancy contributed to LSCS in $87(18.3 \%)$ patients, $39(8.2 \%)$ had ante partum eclampsia. Antepartum hemorrhage (APH) was the indication of surgery in $46(9.7 \%)$ among them placenta previa was found in $31(6.5 \%)$ cases. Malpresetation was the sole indication in $26(5.4 \%) .{ }^{17,18}$ Our results are similar to previous study on the contrary Nazam R et al report that the condition of being previous cesarean section contributes to maximum operative deliveries in their institute in both elective and emergency LSCS. $^{12}$

In agreement with earlier studies atonic post-partum hemorrhage was most commonly met complication in our study contributing in $41(8.6 \%)$ patients irrespective of 
previous surgical history likewise post operatively fever was the most common complication. ${ }^{2,12,13}$ While Jain M et al reports abdominal distension as commonest observed complication. $^{2}$

Perinatal mortality rate of $4.6 \%$ was found in the study which was lower than earlier studies, the profile of neonatal complications observed in present study were in harmony with previous reports, neonatal jaundice being the commonest (215 babies) complication followed by sepsis then birth asphyxia. ${ }^{2}$

Limitation of the study was that, the institute is a tertiary care centre situated in rural area; hence we are getting high risk referral cases which may be the cause of greater number of emergency LSCS. This study does not include cases operated in private sector.

\section{CONCLUSION}

Increased rates of primary CS have led to an increased proportion of the obstetric population with a history of previous caesarean deliveries. The scheme like Janani Suraksha Yajona (JSY) may have a great impact on accepting institutional deliveries by poor women. Rising institutional delivery may be a reason of the increase of $\mathrm{CS}$ in India. Unnecessary caesarean delivery also put strain on family and may complicate maternal and child health. Therefore, the decision to perform a $\mathrm{C}$-section delivery must be chosen carefully.

Increasing incidence of emergency caesarean section may be reduced by encouraging all antenatal women to attend ANC clinics so that those with high risk factors can identified earlier for batter monitoring of labour and elective LSCS if needed.

Funding: No funding sources Conflict of interest: None declared

Ethical approval: Not required

\section{REFERENCES}

1. Lavender T, Hofmeyr GJ, Neilson JP, Kingdon C, Cyte G. Cesarean section for non-medical reasons at term. Cochrane Database Syst Rev. 2006;3:CD004660

2. Jain M, Patel A. A cross sectional study of rate, indications and complications of primary caesarean section. Int J Reprod Contracept Obstet Gynecol. 2016;5:1814-9.

3. Silver RM, Landon MB, Rouse DJ, Leveno KJ, Spong CY, Thom EA, et al. Maternal morbidity associated with multiple repeat cesarean deliveries. Obstet Gynecol. 2006;107:1226-32.

4. Levine EM, Ghai V, Barton JJ, Strom CM. Mode of delivery and the risk for respiratory diseases in newborns. Obstet Gynecol. 2001;97:439-42.
5. Elvedi G, Klepac P, Peter B. Maternal and fetal outcome in elective versus. Coll Antropol. 2006;1(30):113-8.

6. Ali M. Maternal and fetal outcome comparison between emergency and elective caesarean. Professional. 2005;12(1):32-8.

7. World Health Organization, UNFPA, UNICEF and AMDD "monitoring emergency obstetric care: a Handbook", WHO, Geneva. 2009.

8. WHO. Indicators to monitor maternal health goals. Report of a technical working group, Geneva. 1993.

9. IIPS and Macro International: National Family Health Survey (NFHS-3), 2005-06, India. Int Institute Population Sci, Mumbai, 2007.

10. World Health Organization. WHO Statement on Caesarean Section Rates, 2015. Available at apps.who.int/iris/bitstream/10665/161442/1/WHO_R HR_15.02_eng.pdf. Accessed on 20 April 2016.

11. Maternal and child mortality and total fertility rates, sample registration system (SRS). Available at http://censusindia.gov.in/vital_statistics/SRS_Bulleti ns/MMR_release_070711.pdf. Accessed 12 April 2016.

12. Nazam R, Sharma R. Maternal and fetal outcomes in elective and emergency cesarean sections at a teaching hospital in north India. A retrospective study. J Advance Res Bio Sci. 2013;5(1):5-9.

13. Suja D, Manjusha V, Simi BN, Nazeema A. Study of maternal outcome of emergency and elective caesarean section in a semi-rural tertiary hospital. National J Med Res. 2014;4(1):14-8.

14. Loue VA, Gbary EA, Koffi SV, Koffi AK, Traore M, Konan JK, et al. Analysis of caesarean rate and indications of university hospitals in sub-Saharan African developing countries using Robson classification system: the case of Cocody's hospital center, Abidjan-Cote d'Ivoire. Int J Reprod Contracept Obstet Gynecol. 2016;5:1773-7.

15. Lumbiganon $\mathrm{P}$, Laopaiboon $\mathrm{M}$, Gülmezoglu AM, Souza JP, Taneepanichskul S, Pang R, et al. Method of delivery and pregnancy outcomes in Asia: the WHO global survey on maternal and perinatal health 2007-08. Lancet. 2010;375:490-9.

16. Ghazi A, Karim F, Hussain A, Ali T, Jabbar S. Maternal morbidity in emergency. J Ayub Med Coll. 2012;24(1):10-3.

17. Samal R, Palai P, Ghose S. Clinical study of primary caesarean section in multiparous women in a tertiary care hospital. Int $\mathbf{J}$ Reprod Contracept Obstet Gynecol. 2016;5:1506-9.

18. Rahman H, Pradhan D. Rising trends and changed indications of caesarean sections in Sikkim, India: cause for concern? Int J Reprod Contracept Obstet Gynecol. 2016;5:1851-6.

Cite this article as: Yadav S, Kaur S, Yadav SS, Thakur B. Analysis of caesarean rate, indications and complications: review from medical college Ambala, Haryana, India. Int J Reprod Contracept Obstet Gynecol 2016;5:3326-9. 